\title{
Public reporting: Illumination or shadows?
}

\author{
LE Nicolle MD FRCP, Editor-in-Chief
}

$\mathrm{T}_{\mathrm{s}}^{\mathrm{h}}$ The infection control communities in Britain and the United States (US) are experiencing an extraordinary conceptual shift with legislated mandatory reporting of hospital infections. In Britain, this shift began in 2001 with methicillin-resistant Staphylococcus aureus (MRSA) bacteremia episodes (1), which are reported to the National Health Service and are publically available on a Health Protection Agency Web site. In the US, the impetus for public reporting of infection rates has come from consumer groups (2). These organizations have bypassed health care organizations and public health and other practitioners, and have addressed their demands to state legislatures. At least eight states have now passed and several more are considering legislation to mandate reporting. The process has been rancorous and, at least initially, vigorously opposed by health care organizations and infection control practitioners.

The objections raised to public reporting of infection rates include concerns about misinterpretation because of limitations in data quality and the complexity of valid interfacility comparisons, as well as concerns that unfunded mandates such as this parasitize limited resources and compromise program activities of established utility. These are legitimate concerns. Admitting and discharge databases are notoriously unreliable for identification of hospital-acquired infections, and indicators need to be practical and validated. In addition, health care infection rates vary widely with the intensity of surveillance activities. Facilities with less intense case finding will have lower infection rates than facilities with more comprehensive and intense surveillance. Understandably, reports of lower rates will usually be interpreted as a better quality of care. Public reporting may then penalize institutions with superior programs. Patient populations and services provided are highly diverse among institutions. Surgical wound infection rates will differ in obese, elderly individuals with diabetes compared with healthy, young athletes, or for elective laparoscopic cholecystectomy compared with emergency open cholecystectomy. Risk stratification is essential for valid interfacility comparisons but requires greater sophistication and quality of data collection, and more complex analysis.

The experience in Britain with MRSA reporting has already underlined some of these concerns; a summary of the experience over the first three years identifies the number of episodes and rates per 1000 population in different regions of the country (3). While this information shows an overall regional and national trend, it provides little information relevant at the facility level. The conclusion from the initial review was that data were not directly useful due to the following reasons: no accurate measure of workload change; nonuniform ascertainment of MRSA; changes in case mix; regional aggregate reports not reflecting an individual Trust's figures; and the nature of the surveillance not enabling comparison of infection control performance. An analysis of data in Wales (1), which also collected information on medical specialty, had shown variation in MRSA bacteremia rates across specialties from $58 \%$ to $60 \%$ in general surgery to $6.3 \%$ in special care baby units. From June 2005, information identifying the department or specialty where patients were being treated at the time of the infection has also been mandated, with the stated objective of allowing appropriately targeted action with regard to infection control (1). We await further developments.

Even if methodological rigour can be achieved, does the public reporting of rates lead to improvements in patient care? This is the obvious question for health care practitioners in today's milieu of evidence-based medicine. But it is not the goal of the US initiatives - consumer groups have demanded information "to allow consumers to make more informed choices". Does information of uncertain validity from diverse facilities inform choice? In the US, these and other considerations meant initiatives for public reporting were initially denigrated or ignored by health care practitioners and facilities. However, as state after state responded to the consumer initiative and introduced legislation, it became clear that the public reporting agenda would not be derailed. The US Centers for Disease Control and Prevention, together with relevant organizations, including the Society for Healthcare Epidemiology of America (SHEA) and the Association for Professionals in Infection Control and Epidemiology (APIC), have now attempted to manage the process through the publication of a guidance document for reporting (2). This document observes that there is no scientific literature addressing the issue and, therefore, that it is not possible to develop knowledge-based recommendations. It describes the concerns and potential 
problems, then provides general recommendations addressing methodology, oversight of process and outcome measures, implementation and feedback to health care providers. The discussion in the US, however, has moved beyond carping at methods to addressing the information that is now beginning to be reported.

Not surprisingly, these initiatives are catalyzing an even bolder framework of legislated infection control activity. In the United Kingdom, it has been suggested that 'recalcitrant' facilities with persistently high MRSA rates may have 'swat teams' sent to the facility to address the problem. It would be of interest to see the results of such an approach. In Illinois, legislation has recently been introduced to require all facilities to screen for MRSA and "to treat it when it is found". One has visions of hoards of bureaucrats providing antimicrobials for decolonization therapy. Expectations generated by initiatives for public reporting have clearly outstripped science and infrastructure.

Canada has had public reporting of selected health care data for many years. The Canadian Institute for Health Information, in particular, has published interfacility comparisons obtained by mining admitting and discharge data. Attempts to address hospital-acquired infections in these reports, such as surgical wound infection rates, were problematic because the data did not support analysis of the indicator. The Canadian Patient Safety Institute has recently announced a "Safer Healthcare Now!" campaign, with three of six 'strategies' focused on health care-related infections: central line infections, surgical site infections and ventilator-associated pneumonia. Thus, the concept of public reporting is well known to Canadians. However, despite the evolving patient safety movement in Canada, there has not yet been a concerted consumer or legislative call for reporting of facility infections. This may be because the media and legislative focus is on other outcomes - particularly wait times. We in Canada may have the luxury of observing the evolution and

\section{REFERENCES}

1. Johnson AP, Pearson A, Duckworth G. Surveillance and epidemiology of MRSA bacteraemia in the UK. J Antimicrob Chemother 2005;56:455-62.

2. McKibben L, Horan TC, Tokars JI, et al; Healthcare Infection Control Practices Advisory Committee. Guidance on public reporting of healthcare-associated infections: Recommendations of the Healthcare Infection Control Practices Advisory Committee. Infect Control Hosp Epidemiol 2005;26:580-7. application of programs in the US and Great Britain before framing our own strategies.

The public reporting of health care-related infections is attractive if the implementation and reporting of such programs were efficient methods to decrease health care-acquired infections. In fact, studies have repeatedly documented that surveillance with timely reporting back to the practitioners will, by itself, lead to decreased infection rates (4). Public reporting of infection rates could heighten the awareness of not just the public, but also the health care administrators and staff that provide direct patient care, thereby reinforcing appropriate practices. Thus, the concept of public reporting is attractive. Mandatory public reporting could be embraced if adequate infrastructure, training and appropriate methodology accompanied the package. This would include dedicated and appropriately trained personnel and electronic systems for data collection and analysis to support sophisticated risk adjustment and timely reporting. Additional resources would be required for most health care facilities, as well as for program oversight for interfacility comparisons. Education of hospital administrators, legislators, health care funders and the public is also required to support rational interpretation and response to the information generated.

We are all committed to decreasing health care-acquired infections. If public reporting can achieve this, then it should be embraced enthusiastically. These programs, if developed and implemented in partnership with infection control and other stakeholders and with effective leadership and appropriate resources, would raise the profile of hospital infections and, ultimately, increase the quality of hospital infectioncontrol programs. The scenario, however, of unfunded mandates of uncertain benefit but certain erosion of resources only increases cynicism and further alienates practitioners. Public reporting is an opportunity - it should not become a burden.

3. Health Protection Agency. The third year of regional and national analyses of the Department of Health's mandatory MRSA surveillance scheme in England: April 2001 - March 2004. CDR Weekly 2004;14:1-6.

4. Haley RW, Culver DH, White JW, et al. The efficacy of infection surveillance and control programs in preventing nosocomial infections in US hospitals. Am J Epidemiol $1985 ; 121: 182-205$ 


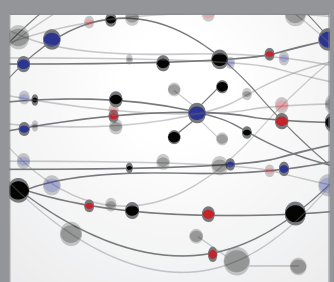

The Scientific World Journal
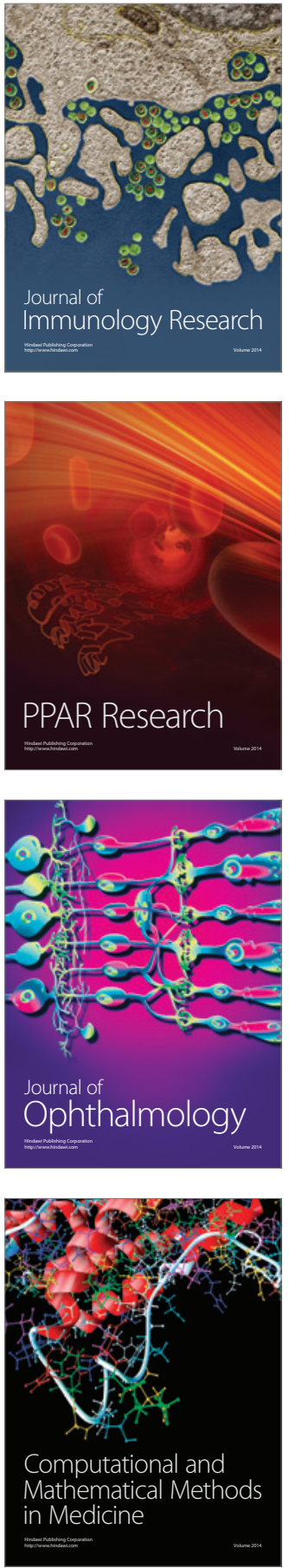

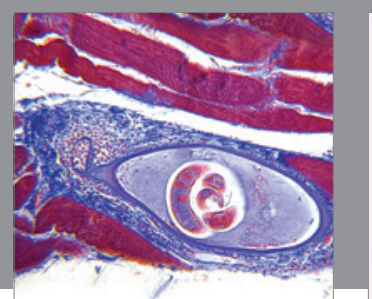

Gastroenterology Research and Practice

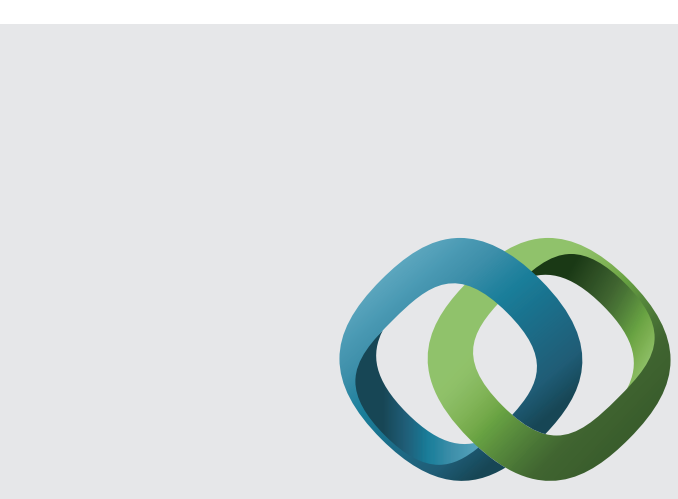

\section{Hindawi}

Submit your manuscripts at

http://www.hindawi.com
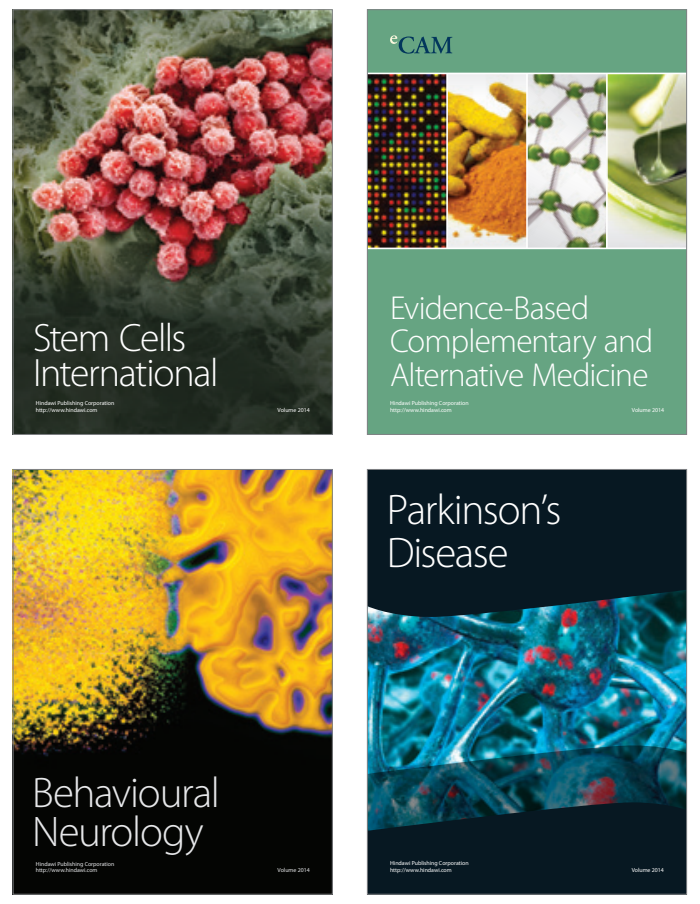
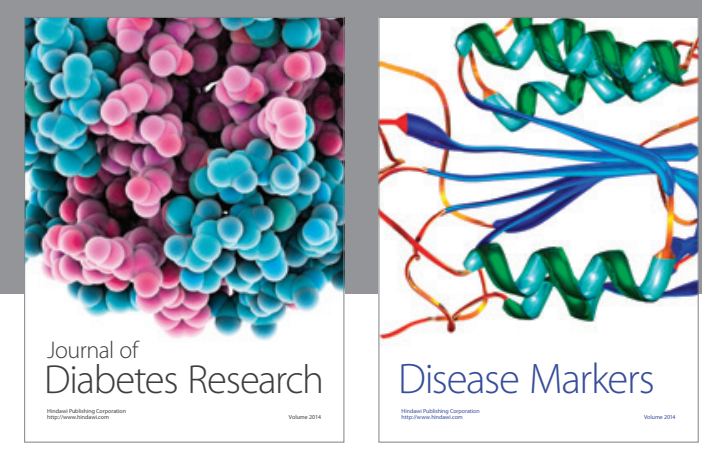

Disease Markers
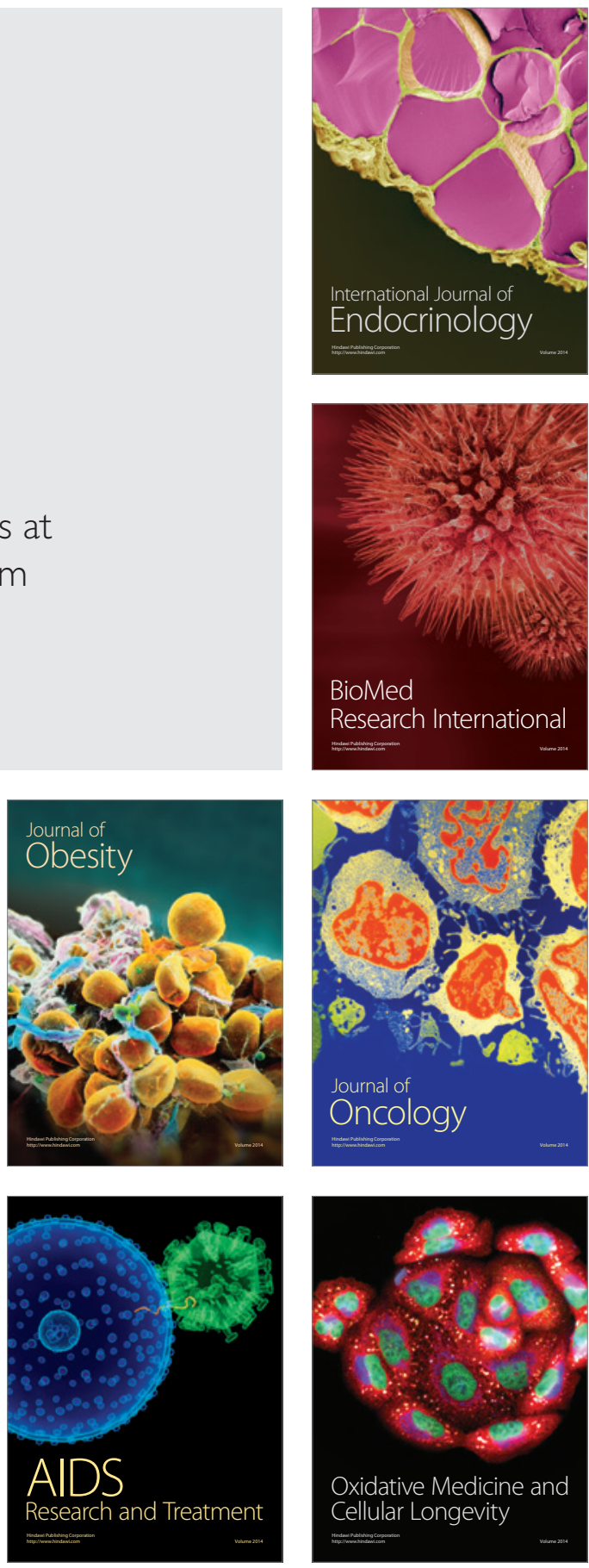